ano 16 - n. 63। janeiro/março - 2016

Belo Horizonte I p. 1-262 I ISSN 1516-3210

A\&C - R. de Dir. Administrativo \& Constitucional

Revista de Direito ADMINISTRATIVO \& CONSTITUCIONAL

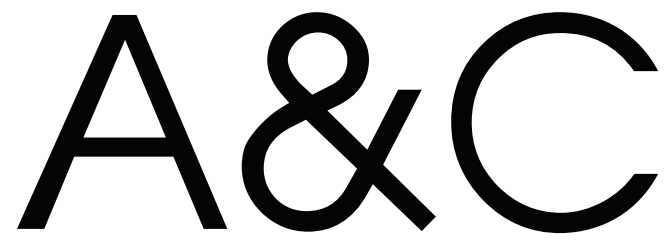




\section{A\&C - REVISTA DE DIREITO ADMINISTRATIVO \& CONSTITUCIONAL}

IPDA

Instituto Paranaense

de Direito Administrativo
ROMEU DELPE

BACELLAR

(c) 2016 Editora Fórum Ltda.

Todos os direitos reservados. É proibida a reprodução total ou parcial, de qualquer forma ou por qualquer meio eletrônico ou mecânico, inclusive através de processos xerográficos, de fotocópias ou de gravação, sem permissão por escrito do possuidor dos direitos de cópias (Lei no 9.610, de 19.02.1998).

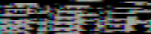

Luís Cláudio Rodrigues Ferreira

Presidente e Editor

Av. Afonso Pena, 2770 - 15a andar - Savassi - CEP 30130-012 - Belo Horizonte/MG - Brasil - Tel.: 08007043737 www.editoraforum.com.br / E-mail: editoraforum@editoraforum.com.br

Impressa no Brasil / Printed in Brazil / Distribuída em todo o Território Nacional

Os conceitos e opiniões expressas nos trabalhos assinados são de responsabilidade exclusiva de seus autores.

\begin{tabular}{|c|c|}
\hline A246 & $\begin{array}{l}\text { A\&C : Revista de Direito Administrativo \& } \\
\text { Constitucional. - ano 3, n. 11, (jan./mar. } \\
\text { 2003)- . - Belo Horizonte: Fórum, 2003- }\end{array}$ \\
\hline & 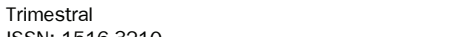 \\
\hline & $\begin{array}{l}\text { Ano 1, n. 1, } 1999 \text { até ano 2, n. 10, } 2002 \text { publicada } \\
\text { pela Editora Juruá em Curitiba }\end{array}$ \\
\hline & $\begin{array}{l}\text { 1. Direito administrativo. } 2 \text {. Direito constitucional. } \\
\text { I. Fórum. }\end{array}$ \\
\hline & $\begin{array}{l}\text { CDD: } 342 \\
\text { CDU: } 342.9\end{array}$ \\
\hline
\end{tabular}

Coordenação editorial: Leonardo Eustáquio Siqueira Araújo Capa: Igor Jamur

Projeto gráfico e diagramação: Walter Santos

\section{Periódico classificado no Estrato A1 do Sistema Qualis da CAPES - Área: Direito.}

Revista do Programa de Pós-graduação do Instituto de Direito Romeu Felipe Bacellar (Instituição de Pesquisa e Pós-Graduação), em convênio com o Instituto Paranaense de Direito Administrativo (entidade associativa de âmbito regional filiada ao Instituto Brasileiro de Direito Administrativo). A linha editorial da $A \& C$ - Revista de Direito Administrativo \& Constitucional segue as diretrizes do Programa de Pós-Graduação do Instituto de Direito Romeu Felipe Bacellar em convênio com o Instituto Paranaense de Direito Administrativo. Procura divulgar as pesquisas desenvolvidas na área de Direito Constitucional e de Direito Administrativo, com foco na questão da efetividade dos seus institutos não só no Brasil como no direito comparado, com ênfase na questão da interação e efetividade dos seus institutos, notadamente América Latina e países europeus de cultura latina.

A publicação é decidida com base em pareceres, respeitando-se o anonimato tanto do autor quanto dos pareceristas (sistema double-blind peer review).

Desde o primeiro número da Revista, $75 \%$ dos artigos publicados (por volume anual) são de autores vinculados a pelo menos cinco instituições distintas do Instituto de Direito Romeu Felipe Bacellar.

A partir do volume referente ao ano de 2008 , pelo menos $15 \%$ dos artigos publicados são de autores filiados a instituições estrangeiras.

Esta publicação está catalogada em:

- Ulrich's Periodicals Directory

- RVBI (Rede Virtual de Bibliotecas - Congresso Nacional)

- Library of Congress (Biblioteca do Congresso dos EUA)

A\&C - Revista de Direito Administrativo \& Constitucional realiza permuta com as seguintes publicações: - Revista da Faculdade de Direito, Universidade de São Paulo (USP), ISSN 0303-9838

- Rivista Diritto Pubblico Comparato ed Europeo, ISBN/EAN 978-88-348-9934-2 
Diretor-Geral

Romeu Felipe Bacellar Filho

Diretor Editorial

Paulo Roberto Ferreira Motta

Editores Acadêmicos Responsáveis

Daniel Wunder Hachem

Ana Cláudia Finger

Assessor Editorial

Felipe Klein Gussoli

\section{Conselho Editorial}

Adilson Abreu Dallari (PUC-SP) Juan Pablo Cajarville Peluffo (Universidad de La República - Uruguai) ardo Schier (Instituto Bacellar) Justo J. Reyna (Universidad Nacional del Litoral - Argentina)

Alice Gonzalez Borges (UFBA) Juarez Freitas (UFRGS)

Carlos Ari Sundfeld (FGV-SP) Luís Enrique Chase Plate (Universidad Nacional de Asunción - Paraguai)

Carlos Ayres Britto (UFSE) Marçal Justen Filho (UFPR)

Adriana da Costa Ricardo Schier (Instituto Bacellar)
Alice Gonzalez Borges (UFBA)

Marcelo Figueiredo (PUC-SP)

Márcio Cammarosano (PUC-SP)

Carlos Delpiazzo (Universidad de La República - Uruguai) Cármen Lúcia Antunes Rocha (PUC Minas) Célio Heitor Guimarães (Instituto Bacellar) Celso Antônio Bandeira de Mello (PUC-SP) Clèmerson Merlin Clève (UFPR) Clovis Beznos (PUC-SP) Edgar Chiuratto Guimarães (Instituto Bacellar) Maria Cristina Cesar de Oliveira (UFPA)

Nelson Figueiredo (UFG)

Odilon Borges Junior (UFES)

Pascual Caiella (Universidad de La Plata - Argentina)

Emerson Gabardo (UFPR)

Paulo Eduardo Garrido Modesto (UFBA)

Paulo Henrique Blasi (UFSC)

Enrique Silva Cimma (Universidad de Chile - Chile) Eros Roberto Grau (USP)

Irmgard Elena Lepenies (Universidad Nacional del Litoral - Argentina) de La Coruña - Espanha)

Pedro Paulo de Almeida Dutra (UFMG)

Regina Maria Macedo Nery Ferrari (UFPR)

Rogério Gesta Leal (UNISC)

Rolando Pantoja Bauzá (Universidad Nacional de Chile - Chile)

Sergio Ferraz (PUC-Rio)

Valmir Pontes Filho (UFCE)

José Eduardo Martins Cardoso (PUC-SP)

José Luís Said (Universidad de Buenos Aires - Argentina) José Mario Serrate Paz (Universidad de Santa Cruz - Bolívia)

Yara Stroppa (PUC-SP)

\section{Homenagem Especial}

Guillermo Andrés Muñoz (in memoriam) Jorge Luís Salomoni (in memoriam) Julio Rodolfo Comadira (in memoriam) Lúcia Valle Figueiredo (in memoriam)

Manoel de Oliveira Franco Sobrinho (in memoriam) Paulo Neves de Carvalho (in memoriam) 


\title{
Sobre princípios e regras: uma crítica à teoria dos princípios de Humberto Ávila
}

\begin{abstract}
Altecir Bertuol Junior
Especialista em Direito Público pelo Instituto Cuiabano de Educação e Especializando em Direito Eleitoral e Improbidade Administrativa pela Fundação Escola Superior do Ministério Público de Mato Grosso (Cuiabá - MT, Brasil). Bacharel em Direito. Autor de artigos publicados em revistas jurídicas. Assistente ministerial do Ministério Público Estadual de Mato Grosso (Grupo de Atuação Especial contra o Crime Organizado - Gaeco). Servidor do Tribunal Regional do Trabalho da 23a Região e ex-assistente de gabinete do Tribunal de Justiça de Mato Grosso. E-mail: <altecir_junior@hotmail.com>.
\end{abstract}

\begin{abstract}
Resumo: 0 neoconstitucionalismo trouxe consigo o pós-positivismo, ideologia que sugere um retorno ao jusnaturalismo sem recorrer a categorias metafísicas, propondo uma leitura moral do direito pautada em valores. Com isso, os princípios, outrora tidos como meras diretivas informadoras sem caráter vinculante, ganham força normativa, assumindo papel central nas Constituições. Nesse contexto, nasce a necessidade de apartar princípios de regras. Este ensaio é desenvolvido no sentido de verificar as teses doutrinárias utilizadas para distinguir as espécies normativas e fazer uma análise criteriosa delas a fim de verificar a sua utilidade, bem como apresentar uma crítica à teoria de Humberto Ávila sobre princípios e regras, apontando suas falhas e acertos.
\end{abstract}

Palavras-chave: Normas constitucionais. Princípios. Regras. Distinção. Neoconstitucionalismo.

Sumário: 1 Introdução - 2 Distinção entre princípios e regras - 3 Conclusão - Referências

\section{Introdução}

A identificação dos elementos de direito aplicáveis a certo grupo de pessoas em determinado momento histórico parece ser trabalho de desenvolvimento contínuo, que tem ocupado juristas de todas as épocas. Os princípios, em especial, têm chamado a atenção acadêmica, fomentando intensos debates ao longo dos anos entre escolas de direito antagônicas.

Em um primeiro momento, concluiu-se que os princípios eram máximas axiológicas de direito natural, sem valor normativo, não sendo, portanto, aplicáveis na solução do conflito apresentado pela situação concreta. Aos poucos restou reconhecido que os princípios integravam o ordenamento jurídico ao lado das normas, sendo, entretanto, distintos destas e desprovidos de caráter vinculante. No constitucionalismo pós-moderno conferiu-se força normativa aos princípios, o que Ihes permitiu ter aplicação direta ao caso concreto como fonte imediata de direitos. 
Destarte, os sistemas jurídicos outrora formados por normas e princípios passaram a ter como elementos de direito princípios e regras, espécies do gênero norma.

Desde então, a doutrina e a jurisprudência têm dispensado pesados esforços para apresentar uma distinção clara entre regras e princípios, do que decorreu o surgimento de vários critérios dispostos a diferenciar essas espécies normativas.

Diante desse contexto, surge o inevitável questionamento: se princípios e regras são normas, como saber quando estamos diante de um ou de outro?

\section{Distinção entre princípios e regras}

\subsection{A distinção entre princípios e regras em Ronald Dworkin}

Dispensando um ataque ideológico contra a doutrina positivista, Dworkin ${ }^{1}$ estabeleceu uma distinção entre regras e princípios dizendo que ambas as espécies normativas se apartam pela natureza da orientação que oferecem. As regras são aplicáveis à maneira do "tudo-ou-nada", pois, dados os fatos concretos que uma regra prevê em seu texto, então, ou a regra é válida, e nesse caso a resposta que ela fornece deve ser aceita, ou não é válida, e nesse caso em nada contribui para a decisão. Os princípios, por outro lado, não apresentam consequências jurídicas a serem automaticamente aplicadas quando as condições fáticas concretas são dadas. Além disso, eles possuem uma dimensão de peso ou importância que as regras não têm.

Ao afirmar que as regras se submetem à sistemática do "tudo-ou-nada" e que elas não possuem a dimensão de peso ou importância, o jurista refere-se à característica de autoaplicação das regras. Nesse contexto, é possível afirmar que toda regra possui dois elementos estruturais, a saber: pressuposto fático e solução jurídica; sendo que a ocorrência daquele serve de propulsão para a aplicação desta. Assim, se verificadas as condições dadas pelo primeiro elemento, aplica-se, automaticamente, o segundo.

Eis o modo de aplicação do "tudo-ou-nada". Diante de um caso concreto, ou se verifica a presença das circunstâncias condicionais à aplicação das regras e sua solução jurídica se concretiza, ou não se constata a presença das condições e ela não se aplica ao caso, hipótese em que é necessário buscar outra regra para solucionar o problema.

A solução do problema da aplicação ou não da regra não apresenta maiores dificuldades quando na hipótese há uma única norma disposta a regulamentar a situação concreta. Todavia, há situações em que se verifica a existência de duas

DWORKIN, Ronald. Levando os direitos a sério. 3. ed. Tradução de Nelson Boeira. São Paulo: Martins Fontes, 2002. p. $40-43$. 
regras que possuem o mesmo pressuposto fático mas apontam soluções jurídicas diversas, sendo ambas, em tese, aplicáveis ao caso concreto. Diante desse quadro a premissa do "tudo-ou-nada" informa que não pode haver duas soluções jurídicas para o mesmo caso, de sorte que uma das regras não pode ser válida. Nesse caso, a decisão acerca da regra válida depende de premissas lógicas dadas pelo ordenamento jurídico em que elas estão inseridas, de "regras, de aceitação generalizada, para resolver conflitos entre normas, pelo menos aqueles simplesmente aparentes". ${ }^{2} \mathrm{~A}$ esse respeito Dworkin explica que: “[...] se duas regras entram em conflito, uma delas não pode ser válida. A decisão de saber qual delas é válida e qual deve ser abandonada ou reformulada, deve ser tomada recorrendo-se a considerações que estão além das próprias regras". ${ }^{3}$

Ao analisar as lições de Dworkin, Vigo ${ }^{4}$ ressalta a dificuldade experimentada na identificação dos princípios decorrente do fato de que, diferente das regras, que se pautam numa decisão de um tribunal ou órgão legislativo, eles tomam por base um sentido de conveniência ou oportunidade que se desenvolve com o tempo, o que torna impossível a confecção de uma lista completa dos princípios com suas respectivas fórmulas canônicas.

\subsection{A distinção entre princípios e regras em Robert Alexy}

Disposto a diferenciar princípios de regras, Alexy ${ }^{5}$ faz uma análise escrupulosa dos critérios utilizados para esse fim, concluindo que todos eles cominam em três teses distintivas das espécies normativas: de acordo com a primeira, não é possível estabelecer nenhuma diferença entre regras e princípios em razão da vasta gama de critérios existentes, posto que são combináveis da maneira que se deseje; a segunda informa que a única diferenciação possível se dá de acordo com o grau de generalidade; por fim, a terceira afirma que há uma distinção não só gradual, mas, também, qualitativa entre princípios e regras.

A partir disso ele concebe os princípios como mandatos de otimização, que devem ser realizados na maior medida possível, podendo, portanto, ser cumpridos em maior ou menor grau, sendo que seu cumprimento somente dependerá das possibilidades jurídicas (determinadas pelas regras e demais princípios opostos) e fáticas existentes. ${ }^{6}$

2 MENDES, Gilmar Ferreira; COELHO, Inocêncio Mártires; BRANCO, Paulo Gustavo Gonet. Curso de direito constitucional. 2. ed. São Paulo: Saraiva, 2008. p. 32.

3 DWORKIN, Ronald. Levando os direitos a sério. 3. ed. Tradução de Nelson Boeira. São Paulo: Martins Fontes, 2002. p. 43.

4 VIGO, Rodolfo Luis. Interpretação jurídica: do modelo juspositivista-legalista do século XIX às novas perspectivas. São Paulo: Revista dos Tribunais, 2005. p. 65.

5 ALEXY, Robert. Teoria de los derechos fundamentales. Madrid: Centro de Estúdios Constitucionales, 1993. p. 84-86.

$6 \quad$ ALEXY, Robert. Teoria de los derechos fundamentales. Madrid: Centro de Estúdios Constitucionales, 1993. p. 86. 
Sob esse prisma a distinção das espécies normativas ocorre com base não só no grau de abstração, mas, também, na essência de cada uma. Assim, se os princípios são mandatos de otimização, de máxima aplicação possível, as regras são mandatos de definição, cujo cumprimento se dá na exata medida prescrita em seu texto. Enquanto uma regra ou incide em sua totalidade ou não recai sobre a situação de fato apresentada, a aplicação dos princípios é modulável, ocorrendo na proporção requerida pela situação concreta, limitada pela incidência concomitante de outras regras ou princípios sobre o mesmo fato.

Em oposição à tese de Alexy, Aarnio ${ }^{7}$ assevera que princípios não podem ser mandatos pois há uma diferença conceitual entre eles. Um mandato de otimização é uma proposição normativa que determina que algo deve ser otimizado, a qual se aproxima de uma regra na medida em que ou se otimiza ou não otimiza. Um princípio jurídico, por sua vez, diz respeito a certos estados ideais de coisas que devem ser alcançados e ao modo de alcançá-los. Portanto, o mandato de otimização recai sobre o princípio determinando que o conteúdo desse seja otimizado em um processo de ponderação.

Essa perspectiva, diz Alexy, não implica um colapso da tese de otimização, apenas dá a essa um foco mais nítido. Sobre esse ponto, o jurista esclarece:

[...] A distinction is to be made between commands to be optimized and commands to optimize. Commands to be optimized are the objects of balancing or weighing. They can be termed "the ideal ought" or "ideals" (Alexy 1995, $203 \mathrm{ff}$.). An ideal "ought" is something that is to be optimized and thereby transformed into a real "ought" (Alexy 1995, 204). As the object of optimization, it is placed on the object level. Contrariwise, the commands to optimize, that is, the optimization commands, are placed on a meta-level. On this level they prescribe what is to be done with that which is found on the object level. They impose the obligation that their subject matter, the commands to be optimized, be realized to the greatest extent possible. As optimization commands they are not to be optimized but to be fulfilled by optimization.

Principles, therefore, as the subject matter of balancing are not optimization commands but rather commands to be optimized. As such they comprehend an ideal 'ought' that is not yet relativized to the actual and legal possibilities. In spite of this, it is useful to talk about principles as optimization commands or obligations. ${ }^{89}$

\footnotetext{
AARNIO, A. Reglas y principios en el razonamiento jurídico. Anuario da Facultade de Dereito da Universidade da Coruña 4. 2000. p. 596-598 apud CIANCIARDO, Juan. Principios y reglas: una aproximación desde los criterios distinción. Boletin Mexicano de Derecho Comparado, año XXXVI, n. 108, set./dic. 2003. Nueva Serie. p. 897. 8 ALEXY, Robert. On the structure of legal principles. Ratio Juris, Oxford, v. 13, n. 3, p. 294-304, Sept. 2000. p. 294-304.

9 “[...] A distinção a ser feita é entre mandatos a serem otimizados e mandatos para otimizar. Mandatos a serem otimizados são objeto de equilíbrio ou ponderação. Eles podem ser denominados de 'deveres ideias' ou 'ideais' (Alexy 1995, 203 e ss.). Um dever ideal é algo a ser otimizado e desse modo transformado em dever 'real' (Alexy 1995, 204). Como objeto de otimização, é colocado no nível de objeto. Por outro lado, os
} 
Outro ponto que distingue princípios de regras é a forma de solução dos conflitos entre normas da mesma espécie.

A superação da contradição instaurada entre duas regras pode ocorrer de duas formas: pela introdução de uma na outra como hipótese de exceção; ou pela declaração de invalidade de uma das normas. ${ }^{10}$ No primeiro caso, se soluciona o conflito fazendo com que uma das regras passe a abarcar a outra, assim, enquanto uma delas é aplicada de forma ordinária, a outra tem sua aplicação mitigada a situações nas quais se verifica determinada peculiaridade diante do caso concreto. A outra solução do embate sugere a aplicação de regras de solução de choque entre regras, que levarão à invalidação de uma das normas em confronto.

Doutra banda, a resolução do problema da colisão entre princípios não se dá no plano da validade, já que ambas as normas são consideradas válidas. No embate entre normas dessa espécie prevalecerá aquela que tenha maior valor (peso) diante da situação concreta.

A prevalência de um princípio sobre o outro exprime uma relação de precedência condicionada entre eles, em que a predominância de um princípio " $A$ " sobre um princípio " $B$ ", ou vice-versa, está condicionada às peculiaridades do caso concreto. ${ }^{11}$ Essa relação de precedência condicionada guarda íntima ligação com as regras, pois elas prescrevem a consequência jurídica a ser aplicada ao caso, diretamente decorrente do princípio prevalecente. Eis a base da "Lei de Colisão": "Las condiciones bajo las cuales un principio precede a otro constituyen el supuesto de hecho de una regla que expresa la consecuencia jurídica del principio precedente". ${ }^{12}{ }^{13}$ Assim, por não ter o elemento "consequência jurídica", o princípio prevalecente não solucionará diretamente a questão concreta posta em análise, ele apenas possibilitará encontrar a regra que contenha a solução jurídica que com ele melhor se relacione.

No mais, Alexy ${ }^{14}$ atesta que as espécies normativas podem ser apartadas pelo seu caráter prima facie. Nesse sentido, ao se analisar os princípios se constata,

mandatos para otimizar, ou seja, os mandatos de otimização, são colocados em um meta-nível. Nesse nível, eles prescrevem o que deve ser feito com o que se encontra no nível do objeto. Eles impõem a obrigação de que seu conteúdo, os mandatos a serem otimizados, sejam realizados na maior extensão possível. Como comandos de otimização eles não devem ser otimizados mas serem cumpridos pela otimização.

Princípios, portanto, como conteúdo de ponderação, não são comandos de otimização, mas, antes, mandatos para serem otimizados. Como tal, compreende um 'dever' ideal que não está ainda relativizado de acordo com as possibilidades legais e reais. Apesar disso, é útil falar em princípios como mandatos de otimização ou obrigações" (Tradução nossa).

10 ALEXY, Robert. Teoria de los derechos fundamentales. Madrid: Centro de Estúdios Constitucionales, 1993. p. 88-89.

11 ALEXY, Robert. Teoria de los derechos fundamentales. Madrid: Centro de Estúdios Constitucionales, 1993. p. 89-95.

12 ALEXY, Robert. Teoria de los derechos fundamentales. Madrid: Centro de Estúdios Constitucionales, 1993. p. 94.

13 "As condições sob as quais um princípio precede a outro constituem o suposto de fato de uma regra que expressa a consequência jurídica do princípio precedente" (tradução nossa).

14 ALEXY, Robert. Teoria de los derechos fundamentales. Madrid: Centro de Estúdios Constitucionales, 1993. p. 98-101. 
de pronto, que eles não são determinados no que se refere às suas possibilidades fáticas e jurídicas. Isso porque, a priori, as soluções por eles apresentadas diante de determinadas condições não implicam resultados definitivos, ante a sua variabilidade de acordo com as circunstâncias, bem como em virtude de que apresentam razões que podem ser desprezadas por outras razões opostas, e, ainda, porque não determinam a consequência jurídica de sua aplicação. Por outro lado, as regras revelam imediatamente suas possibilidades fáticas e jurídicas.

\subsection{Outras distinções entre princípios e regras}

De acordo com as considerações de Novelino, ${ }^{15}$ o critério mais utilizado para separar os princípios das regras é o da abstratividade, que informa que os princípios são normas mais gerais que as regras e que, por isso, enquanto estas comportam inúmeros casos homogêneos, aqueles abarcam casos heterogêneos, o que Ihes confere mais amplo campo de incidência.

Esse pilar comparativo, todavia, é de aceitação controvertida entre os que se dispõem a tentar apartar princípios de regras. Enquanto de um lado diz-se que é imensurável a diferença de generalidade e abstração entre regras e princípios, o que os torna inconfundiveis, ${ }^{16}$ de outro atesta-se que a diferenciação das espécies normativas é impossível diante do alto grau de abstração de algumas regras. ${ }^{17}$ Há, ainda, corrente intermediária que afirma a existência de uma espécie de princípios que não se mistura com os demais princípios ou com as regras, os chamados princípios razoáveis per se, que se encontram em um campo axiológico e, por isso, retiram sua força de si mesmos, sendo, portanto, seu próprio fundamento, ao contrário dos demais princípios e das regras que devem sua força deôntica, preponderantemente, ao juiz e ao legislador que os criou. ${ }^{18}$

Na concepção de Zagrebelsky, ${ }^{19}$ os princípios são desprovidos de "suposto de fato", razão por que nada dizem diretamente sobre situações específicas, embora proporcionem critérios para tomar posição diante de circunstâncias aparentemente indeterminadas, sendo que eles somente terão algum significado operativo se

15 NOVELINO, Marcelo. Direito constitucional. 2. ed. São Paulo: Método, 2008. p. 65.

16 GUERRA FILHO, Willis Santiago. Teses sobre direitos fundamentais, princípios jurídicos e estado democrático de direito. In: ALMEIDA FILHO, Agassiz de; CRUZ, Danielle da Rocha (Coords.). Estado de direito e direitos fundamentais: homenagem ao jurista Mário Moacyr Porto. 1. ed. Rio de Janeiro: Forense, 2005. p. 668.

17 AARNIO, A. Reglas y principios en el razonamiento jurídico. Anuario da Facultade de Dereito da Universidade da Coruña 4. 2000. p. 596-598 apud CIANCIARDO, Juan. Principios y reglas: una aproximación desde los criterios distinción. Boletin Mexicano de Derecho Comparado, año XXXVI, n. 108, set./dic. 2003. Nueva Serie. p. 897.

18 CIANCIARDO, Juan. El ejercicio regular de los derechos: Análisis y crítica del conflictismo. 1. ed. Buenos Aires: Ad-Hoc, 2007. p. 204.

19 ZAGREBELSKY, Gustavo. El derecho dúctil: ley, derechos, justicia. Madrid: Trotta, 1999. p. 110-111 apud MENDES, Gilmar Ferreira; COELHO, Inocêncio Mártires; BRANCO, Paulo Gustavo Gonet. Curso de direito constitucional. 2. ed. São Paulo: Saraiva, 2008. p. 38. 
provocados a reagirem diante de casos concretos. De modo contrário, por serem específicas na sua hipótese de incidência, as regras comportam aplicação mecânica. Às regras se obedece, aos princípios se presta adesão.

Para Canaris ${ }^{20}$ são duas as principais diferenças entre princípios e regras: 0 conteúdo axiológico e o modo de interação com outras normas. Em razão de seu explícito caráter axiológico, que só eles possuem, os princípios necessitam das regras para sua aplicação, enquanto as regras possuem seu sentido devidamente delineado em seu enunciado, os princípios precisam passar por um processo dialético de complementação e limitação.

$\mathrm{Na}$ lição de Canotilho ${ }^{21}$ os princípios jurídicos são normas com um grau de abstração relativamente mais elevado do que o das regras. Por serem vagos e indeterminados, os princípios carecem de mediação para serem concretizados, ao passo que as regras têm aplicação direta. Enquanto as regras são normas vinculativas com um conteúdo meramente funcional, os princípios estabelecem padrões a serem seguidos, standards juridicamente vinculantes. Outrossim, somente os princípios ostentam natureza normogenética, servindo de fundamento para as regras, da mesma forma que apenas eles desempenham papel fundamental no ordenamento jurídico.

No mais, o minucioso estudo de Vigo ${ }^{22}$ enumera a existência de vinte critérios diferenciadores das espécies normativas, os quais tomam por referência o conteúdo, a origem, a validade, a capacidade de justificação, a aplicação, o trabalho exigido, a identificação, a revogação, as exceções, os destinatários, a resolução de contradições, o cumprimento, a estrutura lógica, a incorporação ao sistema jurídico, o compromisso histórico, a localização no ordenamento jurídico, o caráter operativo com a lógica formal, o aporte à completude do sistema, os componentes e as funções.

\subsection{A distinção entre princípios e regras em Humberto Ávila}

\subsubsection{Análise crítica dos critérios distintivos existentes}

A fim de propor seus próprios critérios de diferenciação das espécies normativas, Ávila ${ }^{23}$ analisa os existentes classificando-os e criticando-os.

De acordo com a classificação estruturada pelo jurista, os critérios existentes podem se referir ao caráter hipotético-condicional, ao modo final de aplicação, ao relacionamento normativo e ao fundamento axiológico.

20 CANARIS, Claus-Wilhelm. Systemdenken und systembegriff in der jurisprudenz. Berlin, Duncker und Humblot, 1982. p. 50, 53, 55 apud ÁVILA, Humberto. Teoria dos princípios: da definição à aplicação dos princípios jurídicos. 7. ed. São Paulo: Malheiros, 2007. p. 36.

21 CANOTILHO, José Joaquim Gomes. Direito constitucional. 6. ed. Coimbra: Almedina, 1993. p. 1.034-1.035.

22 VIGO, Rodolfo Luis. Interpretação jurídica: do modelo juspositivista-legalista do século XIX às novas perspectivas. São Paulo: Revista dos Tribunais, 2005. p. 143-149.

23 ÁVILA, Humberto. Teoria dos princípios: da definição à aplicação dos princípios jurídicos. 7. ed. São Paulo: Malheiros, 2007. p. 40-64. 
O caráter hipotético-condicional informa que as regras possuem uma hipótese de incidência e uma consequência jurídica que predeterminam a decisão, sendo, então, aplicadas ao modo "se/então". Os princípios, entretanto, apenas indicam o fundamento a ser utilizado pelo aplicador para encontrar a regra para o caso concreto.

Na visão de Ávila a identificação da espécie da norma não decorre necessariamente da maneira como ela é formulada, pois a hipótese de incidência é uma questão de formulação linguística que permite reescrever os princípios a partir da mesma estrutura linguística atribuída às regras, com uma hipótese de incidência e uma consequência jurídica. Assim, ainda que uma norma seja hipoteticamente formulada como regra ou princípio, não é a forma dada pelo legislador que a caracteriza, mas a atividade interpretativa do aplicador, de modo que a norma pode assumir a forma ora de princípio, ora de regra.

O modo final de aplicação sugere que as regras sejam aplicadas ao modo do "tudo-ou-nada" e os princípios ao modo do "mais-ou-menos".

Os critérios que tomam por base essa diretiva, diz o catedrático, não são capazes de distinguir as espécies normativas porque a maneira como a norma será aplicada não é determinada pelo seu texto, mas pela atividade interpretativa. Nessa esteira, não é possível obedecer de modo absoluto aos métodos do "tudo-ou-nada", atribuído às regras, e do "mais-ou-menos", empregado aos princípios, pois a consequência jurídica estabelecida no enunciado de uma regra pode, mediante fundamentação, deixar de ser aplicada em função das razões substanciais do caso concreto, em que tais razões são tidas como mais importantes do que aquelas que originam a própria regra afastada, hipótese em que a regra será aplicada ao modo "mais-oumenos", típico dos princípios. Ademais, as regras deixam de ser aplicadas ao modo "tudo-ou-nada" na hipótese de analogia, pois elas são aplicadas sem que haja o preenchimento do pressuposto de fato nelas descrito, além do que, assim como os princípios, elas necessitam de um processo prévio de interpretação que demonstre quais as consequências que serão implementadas.

Nesse sentido, a distinção não reside no modo final de aplicação, mas na maneira pela qual o intérprete justifica a aplicação dos significados preliminares dos dispositivos, já que ambas as espécies de normas carecem de ponderação no momento de sua aplicação. Assim, na argumentação as regras são razões de correção ou razões autorizativas, pois a própria norma serve de motivo para a adoção do comportamento nela descrito. Os princípios, por sua vez, estabelecem estados de coisas, por isso sua aplicação não descreve diretamente o comportamento devido, portanto, eles figuram como razões substanciais ou finalísticas para a argumentação.

A diretiva do relacionamento normativo revela que o conflito de regras é solucionado pela invalidação de uma das normas ou pela inclusão de uma como cláusula de exceção da outra, ao passo que a colisão entre princípios se resolve pela ponderação de valores, sendo veementemente repudiada sob o argumento de que a 
ponderação não é método privativo de aplicação dos princípios, já que também as regras podem entrar em choque no plano concreto, sendo possivel atribuir-lhes um peso ou valor de modo a afastar a invalidação de qualquer das regras conflitantes.

A premissa do fundamento axiológico considera os princípios, ao contrário das regras, como fundamentos axiológicos para a decisão a ser tomada.

\subsubsection{Apresentação de novos critérios}

De acordo com Ávila ${ }^{24}$ os critérios existentes utilizados para separar princípios de regras são falhos e insuficientes, sendo necessária a formulação de novas balizas, razão por que ele apresenta os critérios da natureza do comportamento descrito, da natureza da justificação exigida e da medida de contribuição para a decisão.

0 critério da natureza do comportamento descrito na norma prescreve que as regras são imediatamente descritivas, preveem condutas determinando aquilo que deve ou não ser feito, sendo, por isso, chamadas de "normas do que fazer" (oughtto-do-norms), enquanto que os princípios são normas imediatamente finalísticas, estabelecem o estado ideal das coisas, que deve ser buscado pela prática de condutas cuja escolha cabe ao intérprete da norma, são "normas do que deve ser" (ought-to-be-norms). Assim, os princípios indicam fins a serem perseguidos, ao passo que as regras determinam condutas para o alcance desses fins.

Além disso, as regras assumem caráter retrospectivo, pois abarcam situações de fato conhecidas do legislador. Os princípios, doutra banda, têm caráter prospectivo, estabelecem um fim a ser alcançado com a finalidade de abranger situações não conhecidas pelo legislador ou situações de número e peculiaridades por demais abundantes que impeçam seu lançamento em rol taxativo ou a apresentação de solução única.

Também o ônus argumentativo exigido na aplicação da norma pode revelar a sua espécie. 0 critério da natureza da justificação exigida para a aplicação da norma informa que as regras ostentam um grau de argumentação instável, que se mostra tênue, quando o suposto de fato descrito na norma se adequa perfeitamente ao caso, servindo, então, de justificação para sua aplicação, ou robusto, diante de casos dificeis (hard cases), ao passo que os princípios, de forma diversa, possuem ônus argumentativo estável, pois a carga argumentativa requerida é sempre pesada, não havendo, então, casos fáceis ou difíceis. A aplicação dos princípios requer sempre o desenvolvimento de determinado raciocínio diante da situação concreta exposta a fim de verificar se as condutas praticadas ou praticáveis são enquadráveis no rol daquelas que se voltam à realização do princípio objeto de análise.

\footnotetext{
${ }_{24}$ ÁVILA, Humberto. Teoria dos princípios: da definição à aplicação dos princípios jurídicos. 7. ed. São Paulo: Malheiros, 2007. p. 71-78.
} 
A forma como cada uma das espécies normativas contribui para a decisão também denuncia sua natureza. 0 critério da medida da contribuição para a decisão estabelece que as regras têm pretensão terminativa, são normas preliminarmente decisivas porque buscam gerar uma solução específica para determinada questão ao enquadrar a realidade fática em seu elemento fático hipotético, aplicando a solução jurídica que traz em seu bojo, exceto quando verificada a sua aptidão para cancelamento - quando, em razão das peculiaridades da situação, não são aplicadas; os princípios, por seu turno, têm pretensão de complementaridade, pois não intentam gerar uma solução direta para o caso, buscam apenas contribuir para a decisão ao lado de outros elementos normativos.

$\mathrm{Na}$ aplicação simultânea desses critérios, princípios e regras podem ser assim definidos:

As regras são normas imediatamente descritivas, primariamente retrospectivas e com pretensão de decidibilidade e abrangência, para cuja aplicação se exige a avaliação da correspondência, sempre centrada na finalidade que Ihes dá suporte ou nos princípios que Ihes são axiologicamente sobrejacentes, entre a construção conceitual da descrição normativa e a construção conceitual dos fatos.

Os princípios são normas imediatamente finalísticas, primariamente prospectivas e com pretensão de complementaridade e de parcialidade, para cuja aplicação se demanda uma avaliação da correlação entre o estado de coisas a ser promovido e os efeitos decorrentes da conduta havida como necessária à sua promoção. ${ }^{25}$

\subsection{Análise crítica das ideias de Humberto Ávila}

As críticas de Ávila aos critérios existentes, embora relevantes, devem ser vistas com a devida ressalva, sendo, por isso, pertinente que se faça algumas ponderações.

A respeito da censura sobre os critérios que consideram o caráter hipotéticocondicional se deve anotar que o legislador não define a natureza da norma pela formulação linguística de seu texto, pois a estrutura textual pela qual a norma se apresenta decorre diretamente de suas características essenciais, demonstradas pelos estudos de, entre outros, Alexy e Dworkin.

Por expressarem padrões a serem buscados, os princípios jamais indicarão diretamente a solução jurídica para o caso concreto, eles apenas permitirão verificar se o estado ideal que estabelecem foi perseguido ou não, ou eles são observados ou não.

\footnotetext{
25 ÁVILA, Humberto. Teoria dos princípios: da definição à aplicação dos princípios jurídicos. 7. ed. São Paulo: Malheiros, 2007. p. 78-79.
} 
Ao justificar sua crítica, Ávila apresenta os exemplos a seguir voltados a demonstrar que é possível reestruturar a dicção de um princípio para que ele se apresente como uma regra:

De fato, algumas normas que são qualificáveis, segundo esse critério, como princípios podem ser reformuladas de modo hipotético, como demonstram os seguintes exemplos: "Se o poder estatal for exercido, então deve ser garantida a participação democrática" (princípio democrático); "Se for desobedecida a exigência de determinação da hipótese de incidência de normas que instituem obrigações, então o ato estatal será considerado inválido" (princípio da tipicidade). ${ }^{26}$ (Grifos no original)

Essas reformulações, todavia, apenas fazem com que o princípio deixe de se apresentar por um enunciado direto de "dever ser" para ser visto como um conjunto de proposições de lógica, pois a conclusão - proposição "então" - não apresenta uma consequência jurídica na forma de uma solução direta para o caso concreto como ocorre com as regras, mas, unicamente, uma mera constatação que se soma à proposição "se" para revelar o conteúdo do princípio, como ocorre claramente no exemplo do princípio democrático.

A alegada possibilidade de reestruturação linguística não tem o condão de transformar regra em princípio ou princípio em regra, posto que as regras sempre conterão seus elementos característicos - pressuposto fático e consequência jurídica -, enquanto que os princípios, não importa a forma como seus textos sejam apresentados, jamais trarão a solução diretamente aplicável ao caso (consequência jurídica).

A fim de ilustrar tal afirmação, se passa à análise de alguns princípios operantes no direito pátrio.

O inc. LIV do art. 5ํo da Constituição da República de 1988 prevê expressamente o princípio do devido processo legal sob a seguinte redação: "ninguém será privado da liberdade ou de seus bens sem o devido processo legal”. Utilizando-se da sistemática da reformulação linguística apontada por Ávila, seria possível apresentar o princípio em questão, em sua faceta processual, da seguinte forma: se o processo observa todas as regras procedimentais, então é válido/regular, restando resguardados os direitos de liberdade e patrimoniais do indivíduo. Como se vê não há qualquer consequência jurídica direta apontada no princípio, posto que ele oferece um padrão que se verifica ter sido seguido ou não, ou as regras procedimentais foram observadas ou não, ou os direitos de liberdade e patrimoniais do indivíduo foram resguardados ou não.

\footnotetext{
26 ÁVILA, Humberto. Teoria dos princípios: da definição à aplicação dos princípios jurídicos. 7. ed. São Paulo: Malheiros, 2007. p. 41.
} 
0 art. 5ำ, caput, da Lei Suprema expõe o princípio da isonomia dispondo que "todos são iguais perante a lei". Reescrito à maneira do "se/então", o princípio informaria que "se todos devem se submeter ao império da lei, então ela deve ser aplicada a todos igualmente". Aplicado a uma situação concreta o princípio permitiria verificar se o estado ideal de igualdade nele descrito foi buscado ou não, ou se constata que a lei foi aplicada de forma isonômica ou se verifica que não foi, não havendo, no entanto, consequência jurídica direta para essa inobservância, apenas a constatação da dispensação de tratamento legal igualitário ou não.

Como se vê nessa rearticulação textual dos princípios, a proposição "então" aponta para uma constatação de que, no caso concreto, ou o princípio foi observado e se prestou adesão a ele, ou não foi observado, não tendo havido, dessa forma, sua adesão.

Por fim, resta indagar: o que dizer do princípio da dignidade da pessoa humana? Como reestruturar sua dicção linguística na forma como são elaboradas as regras? Com efeito, seria impossível, em um primeiro momento, reajustar a construção linguística do princípio da dignidade da pessoa humana, posto que a proposição "se" somente seria passível de ser formulada diante do caso concreto e quando já se houvesse concluído que aquela situação fática viola a dignidade humana. Além disso, a proposição "então" seria invariável, apontando sempre para a constatação de que o estado ideal não foi observado, ou seja, o princípio foi infringido, contudo, sem apontar consequência jurídica direta.

Conclui-se, portanto, que não procede a observação feita por Ávila de que a hipótese de incidência é uma questão de formulação linguística e que os princípios podem, da mesma forma que as regras, ser escritos ao modo "se/então". Em verdade, os princípios até podem se utilizar dessa prática, contudo, não se trata de uma questão meramente linguística, pois o que se observa dos ensinamentos de Alexy é que, como exposto alhures, as regras possuem, ordinariamente, dois elementos que as compõem - hipótese de incidência e consequência jurídica -, que não são comportados pelos princípios, posto que, ainda que esses tenham sua dicção formulada ao modo "se/então", não admitem o elemento consequência jurídica direta, já que revelam apenas uma constatação de que, de modo genérico, ou o princípio foi observado - o estado ideal nele representado foi aderido - ou não - o estado ideal não foi aderido. Logo, por descreverem estados ideais de coisas, os princípios não apontam para consequências jurídicas diretas, as quais são reveladas pela aplicação da "Lei de Colisão" de Alexy.

A concepção de que as normas ora assumem forma de regras ora de princípios, dependendo da atividade do intérprete, não é indene de crítica. Nessa perspectiva não há diferença, prima facie, entre as espécies normativas. Ora, se uma norma pode assumir forma de regra ou de princípio de acordo com o caso apresentado, 
dependendo da variação do trabalho do intérprete, de modo que a diferenciação entre um e outro somente se revelará no momento em que forem aplicados, então não há que se falar em espécies normativas, concebendo-se a existência unicamente de normas.

A crítica dispensada aos critérios que tomam por base o modo final de aplicação das normas é, com a devida vênia, equivocada. Ao rechaçar a premissa do "tudoou-nada", Ávila defende que embora presente a premissa fática descrita na regra proposição "se" -, se as circunstâncias concretas do caso forem capazes de justificar a sua não aplicação, não será aplicada a solução jurídica - proposição "então" - que ela traz consigo, razão por que a premissa em questão não serviria para distinguir as espécies normativas.

No cenário apresentado não há qualquer alteração quanto ao modo de aplicação das regras, pois se a consequência jurídica não pode ser aplicada, então a regra, em sua totalidade, não é aplicada ao caso, restando configurada, assim, a hipótese do "nada", circunstância em que, se necessário, se deve buscar aplicar outra regra para a solução do problema exposto pelo caso concreto. Logo, na hipótese idealizada pelo jurista, a aplicação da regra ocorre ao modo do "tudo-ou-nada”, já que ela não é aplicada parcialmente, mas, simplesmente, não é aplicada.

Outro aspecto do mesmo argumento indicado pelo catedrático para sustentar a imprestabilidade do critério do "tudo-ou-nada" aponta para o fato de que as regras, assim como os princípios, precisariam de um processo de interpretação que revelasse as consequências jurídicas a serem aplicadas. Ora, de fato a interpretação é ínsita a todas as normas. Jamais se disse que as regras não necessitam de interpretação. Deveras, somente se pode conhecer o preceito contido num texto legal após a sua interpretação. Ademais, se a interpretação de uma regra sugerir o afastamento desta em determinado caso concreto em razão de peculiaridades apresentadas, então a interpretação daquela regra não está apontando a consequência jurídica a ser aplicada naquele caso, mas a própria regra, na medida em que será necessário buscar outra norma para solucionar a questão.

É errônea a assertiva de que não se mostra coerente afirmar que toda vez que constatada a hipótese de incidência de uma regra essa deverá ser diretamente implementada por haver ocasiões em que a consequência jurídica de uma regra é aplicada mesmo não estando configurada a sua hipótese de incidência, o que ocorre na solução de uma questão pela analogia.

A utilização da analogia é um método necessário de integração das normas, não sendo mera faculdade, mas um dever do juiz diante da ausência de norma específica. $\mathrm{Na}$ aplicação da analogia se concebe a existência de duas regras: a regra modelo, emanada do poder competente, que serve de base para a formulação da regra decorrente; e a regra decorrente, criada pelo juiz diante da situação concreta, 
com base na regra modelo, mediante permissão legal consistente em uma espécie de delegação. Assim sendo, diante do caso concreto, ante a ausência de regra específica, cabe ao juiz formular a regra não escrita a ser aplicada, seguindo a orientação da mens legislatoris, a qual terá como suposto de fato a circunstância concreta apresentada e como consequência jurídica aquela contida na regra modelo.

Portanto, não há que se falar que o modo do "tudo-ou-nada" não serve como critério de distinção entre regras e princípios, posto que totalmente aplicável na forma como concebido por seus idealizadores.

A ideia de que as regras também podem ser aplicadas ao modo do "maisou-menos", típico dos princípios, quando contiverem enunciados abertos, não é aceitável. Nessa circunstância, diz Ávila, ficaria a cargo do intérprete decidir pela aplicação ou não da regra ao caso concreto.

Essa concepção é contraditória, pois como se pode afirmar que uma norma é aplicada ao modo do "mais-ou-menos" se cabe ao intérprete decidir se ela será ou não aplicada à situação concreta? Aplicar uma norma à maneira do "mais-oumenos" é dizer que ela será aplicada em maior ou menor grau, não se concebendo a possibilidade de rejeitá-la.

A fim de esclarecer sua visão, Ávila dá o exemplo da imunidade tributária estabelecida para livros no art. 150, VI, "d", da Lei Magna, que dispõe que é vedado à União, aos estados, ao Distrito Federal e aos municípios instituir impostos sobre livros, jornais, periódicos e o papel destinado à sua impressão. Em sua concepção, essa seria uma regra aplicável ao modo do "mais-ou-menos" porque cabe ao intérprete decidir se a regra será aplicada quando se tratar de livros eletrônicos.

Deixando de lado a questão da definição da natureza da norma que estabelece a imunidade em questão, não se pode deixar de esclarecer que a hipótese dada pelo jurista não trata de aplicação em maior ou menor grau da regra, mas de mera atividade interpretativa, necessária ao emprego de qualquer espécie normativa, que irá definir se o livro eletrônico encontra ou não subsunção ao elemento fático da regra que contém o vocábulo "livros". Se eventualmente o intérprete concluir pela aplicação da norma, terá simplesmente, se valendo de uma interpretação extensiva, verificado que a norma contida no texto é mais ampla do que o próprio texto. Não se terá, portanto, uma aplicação da regra ao modo do "mais-ou-menos", mas à maneira do "tudo-ou-nada”, já que a circunstância concreta representada pelos livros eletrônicos encontrou abrigo no suposto fático abstrato da norma revelado na palavra "livros", razão por que a norma foi aplicada em sua totalidade, sem qualquer graduação.

Assim sendo, o modo de aplicação do "mais-ou-menos" como critério distintivo entre princípios e regras é válido, visto que aplicável apenas àqueles.

Em última análise, a perspectiva de Ávila revela questões intrínsecas da interpretação das normas, prática necessária a qualquer espécie normativa, as quais 
não se confundem com os métodos de aplicação da norma, seja ele o "tudo-ou-nada" ou o "mais-ou-menos", pois uma coisa é o trabalho de integração dos fatos à norma e outra bem diferente é saber, após se constatar a incidência da norma sobre os fatos, de que modo ela será aplicada.

A crítica sobre os critérios que consideram o conflito normativo, pautada na premissa de que as regras podem, assim como os princípios, entrar em conflito no plano concreto, de modo que é possível atribuir-Ihes um valor ou peso, comporta acolhimento parcial.

Isso porque, tomando a ponderação como técnica de sopesamento de razões e contrarrazões que culmina em uma decisão de interpretação, é possível verificar que as regras, assim como os princípios, a ela se submetem. Da mesma forma, é possivel reconhecer que, assim como ocorre com os princípios, as regras entram em conflito no campo concreto.

Todavia, isso não significa dizer que é possível atribuir um valor a cada regra para solucionar o conflito normativo. Aliás, a proposição de Ávila não contraria as formulações feitas por Alexy, mas as complementa. Isso porque ao afirmar que "em alguns casos as regras entram em conflito sem que percam sua validade", ${ }^{27}$ aquele está simplesmente confirmando a convicção deste a respeito da solução do confronto de regras pela inclusão da cláusula de exceção, pois a atividade de ponderação será utilizada para justificar a não aplicação de uma regra ao caso concreto, embora esteja configurado o elemento fático nela descrito, atividade que nada mais é do que a inclusão de uma cláusula de exceção. Nesse diapasão, a proposta deve ser analisada com a devida ressalva.

Para ilustrar sua reflexão, o jurisconsulto se utiliza dos seguintes exemplos:

Primeiro exemplo: uma regra do Código de Ética Médica determina que o médico deve dizer para seu paciente toda a verdade sobre sua doença, e outra estabelece que o médico deve utilizar todos os meios disponíveis para curar seu paciente. Mas como deliberar o que fazer no caso em que dizer a verdade ao paciente sobre sua doença irá diminuir as chances de cura, em razão do abalo emocional daí decorrente? O médico deve dizer ou omitir a verdade? Casos hipotéticos como esse não só demonstram que o conflito entre regras não é necessariamente estabelecido em nível abstrato, mas pode surgir no plano concreto, como ocorre normalmente com os princípios. Esses casos também indicam que a decisão envolve uma atividade de sopesamento entre razões.

Segundo exemplo: uma regra proíbe a concessão de liminar contra a Fazenda Pública que esgote o objeto litigioso (art. 1ํ da Lei 9.494/1997). Essa regra proíbe ao juiz determinar, por medida liminar, o fornecimento de remédios pelo sistema de saúde a quem deles necessitar para viver.

\footnotetext{
27 ÁVILA, Humberto. Teoria dos princípios: da definição à aplicação dos princípios jurídicos. 7. ed. São Paulo: Malheiros, 2007. p. 52.
} 
Outra regra, porém, determina que o Estado deve fornecer, de forma gratuita, medicamentos excepcionais para pessoas que não puderem prover as despesas com os referidos medicamentos (art. 1으 da Lei Estadual 9.908/1993). Essa regra obriga a que o juiz determine, inclusive por medida liminar, o fornecimento de remédios pelo sistema de saúde a quem deles necessitar para viver. Embora essas regras instituam comportamentos contraditórios, uma determinando o que a outra proíbe, elas ultrapassam o conflito abstrato mantendo sua validade. Não é absolutamente necessário declarar a nulidade de uma das regras, nem abrir uma exceção a uma delas. Não há a exigência de colocar uma regra dentro e outra fora do ordenamento jurídico. 0 que ocorre é um conflito concreto entre as regras, de tal sorte que o julgador deverá atribuir um peso maior a uma das duas, em razão da finalidade que cada uma delas visa a preservar: ou prevalece a finalidade de preservar a vida do cidadão, ou se sobrepõe a finalidade de garantir a intangibilidade da destinação já dada pelo Poder Público às suas receitas. Independentemente da solução a ser dada - cuja análise é ora impertinente -, trata-se de um conflito concreto entre regras, cuja solução, sobre não estar no nível da validade, e sim no plano da aplicação, depende de uma ponderação entre as finalidades que estão em jogo. ${ }^{28}$

$\mathrm{Na}$ questão relativa à ética médica, ao concluir que a primeira regra não deve ser aplicada nos casos em que seu emprego pode piorar o quadro clínico do paciente, o intérprete da norma nada mais estará fazendo do que inserindo uma das regras como cláusula de exceção da outra, exatamente como idealizado por Alexy, de forma que o resultado da interpretação será: o médico deverá sempre dizer a verdade a seu paciente sobre sua doença, salvo se isso puder levar à piora de seu quadro clínico.

Na mesma esteira segue a hipótese da liminar contra a Fazenda Pública. Embora as regras expostas não regulem a mesma conduta, não há como negar que elas podem entrar em confronto diante de uma situação concreta em que alguém, se baseando na obrigação do Estado de fornecer os medicamentos, ingressa contra esse em juízo rogando que Ihe seja imposta tal obrigação em sede de antecipação dos efeitos da tutela. Também nesse caso a conclusão do intérprete pela concessão da medida que ordena que o Estado entregue o medicamento configura a inclusão de uma cláusula de exceção à regra que proíbe a antecipação em demandas contra a Fazenda Pública, sendo possível formular a regra da seguinte forma: não será concedida a antecipação da tutela nas ações contra o Estado, salvo quando se tratar de obrigação de entrega de medicamento.

Com efeito, essa situação também poderia ser solucionada pela aplicação da "Lei de Colisão" de Alexy. De fato, a situação apresentada pode configurar uma colisão entre princípios: de um lado o princípio da supremacia do interesse público,

28 ÁVILA, Humberto. Teoria dos princípios: da definição à aplicação dos princípios jurídicos. 7. ed. São Paulo: Malheiros, 2007. p. 53-54. 
que justifica a prerrogativa processual em favor do Estado de não ter contra si decisão que defira tutela de urgência, de outro, o princípio da dignidade da pessoa humana, que traz em seu bojo os direitos fundamentais à saúde e à vida. Aplicando-se a "Lei de Colisão", tem-se que: se diante da circunstância apresentada, o princípio da dignidade da pessoa humana prevalece sobre o princípio da supremacia do interesse público; se essa relação de prevalência deve ter uma consequência jurídica; se a consequência jurídica é dada por uma regra; então vale a regra que determina que o Estado entregue o medicamento, pois a condição sob a qual o princípio da dignidade da pessoa humana é predominante constitui o suposto de fato dessa regra, que é revelado no momento da aplicação da "Lei de Colisão".

Conclui-se, então, que neste ponto as ponderações de Ávila, em parte, vêm ao encontro das formulações de Alexy a respeito dos conflitos entre regras, melhorando esse protótipo para esclarecer que o confronto entre normas dessa espécie pode ocorrer tanto no plano abstrato, quando regularem uma mesma conduta de maneira diferente, ou seja, quando possuírem a mesma circunstância fática mas resoluções jurídicas diversas, como no concreto, hipótese em que mesmo não regulando a mesma conduta apresentarem comandos opostos, de maneira que naquela seara haverá a invalidação de uma das regras, enquanto neste campo valer-se-á o intérprete da ponderação - entendida como sopesamento de razões e contrarrazões - para incluir a cláusula de exceção.

\section{Conclusão}

Em última análise, é possível afirmar que os critérios até então disseminados para separar princípios de regras não são antagônicos, mas convergentes, posto que uns complementam os outros, de modo que, ante uma situação concreta, se uns ou alguns dos critérios se mostrarem insuficientes para que se realize a distinção, é possivel recorrer a outros.

Nesse sentido, retomando os critérios descritos por Canotilho, é possível afirmar que, embora seja procedente a crítica feita ao critério do grau de abstração, fato é que, salvo nos casos em que as regras forem altamente abstratas, esse será um critério válido, já que, a rigor, é possível distinguir os tipos normativos sob tal prisma e, não sendo possível, há que se recorrer a outro critério.

Da mesma forma, o grau de determinabilidade não deve ser descartado de plano, mas, apenas nos casos em que se mostrar insuficiente, pois, de fato, em razão da ausência do elemento estrutural que aponta a solução jurídica, os princípios necessitam de mediação diante do caso concreto.

É correta, também, em relação a alguns princípios, a premissa de que possuem papel fundamental - critério do caráter de fundamentalidade -, já que determinados 
princípios têm essa característica, como exemplo, o princípio federativo, caráter que não se amolda a qualquer tipo de regra.

Válido, da mesma forma, é o critério da proximidade da ideia de direito, já que as regras são criadas para atuarem de modo funcional, regulando uma situação específica antevista pelo legislador, mas que, se aplicadas indistintamente, sem observância das peculiaridades do caso, podem se afastar do ideal de direito, justiça e equidade, sendo que os princípios, por outro lado, têm base jusnatural que converge para esse sentido.

Sem embargo, é inegável que os princípios têm a característica de servir de base para a criação das regras - critério da natureza normogenética -, contudo, a recíproca não é verdadeira.

Entrementes, o critério do "tudo-ou-nada" idealizado por Dworkin, aplicável às regras, e a ideia de peso ou valor, atribuído aos princípios, coadunam-se com a proposta de Zagrebelsky, quando esse afirma que às regras se obedece e aos princípios se presta adesão, bem como que as regras são aplicadas de maneira mecânica e passiva, da mesma forma que se amolda à ideia de Canotilho quando afirma que as regras possuem conteúdo funcional.

Ressalte-se que dizer que uma norma é aplicável ao modo do "tudo-ou-nada" não contradiz os critérios da fundamentalidade, da proximidade da ideia de direito, do grau de determinabilidade ou da abstração, pois todos eles podem ser utilizados numa mesma situação, de modo que uma norma será regra quando não contiver caráter fundamental, possuir baixo grau de abstração, quando for de aplicação direta e ao modo do "tudo-ou-nada" - sendo válida ou não.

As formulações de Alexy também se voltam para o mesmo sentido, posto que se baseiam na ideia de Dworkin do "tudo-ou-nada" para formular a "regra de exceção".

Da mesma maneira, a "Lei de Colisão" não se distancia do critério da determinabilidade, segundo o qual os princípios carecem de mediações concretizadoras, nem mesmo da ideia de Zagrebelsky, que afirma que os princípios não têm "suposto de fato".

Verifica-se, igualmente, a compatibilidade de ideias ao se analisar a disposição sobre a colisão de princípios de Alexy - segundo a qual um dos princípios prevalecerá sobre o outro sob determinadas condições por possuir maior valor na situação específica -, a dimensão do valor dos princípios de Dworkin e o dizer de Zagrebelsky a respeito da prestação de adesão aos princípios por expressarem valores. Nenhuma afronta, igualmente, se verifica por parte desses critérios em relação àqueles apresentados por Claus-Wilhelm Canaris, que afirma que os princípios têm conteúdo axiológico - o que se harmoniza com o critério da proximidade da ideia de direito de Canotilho - e que as regras têm seu sentido apresentado em seu enunciado enquanto os princípios necessitam de um processo de complementação e limitação 
- o que se coaduna com a ideia de Zagrebelsky sobre a ausência do "suposto de fato" nos princípios, bem como com as formulações de Alexy a respeito da colisão de princípios e a "Lei de Colisão".

Cumpre anotar, ainda, que em relação aos critérios apresentados por Ávila, quais sejam, da natureza do comportamento descrito, da natureza da justificação exigida e da medida de contribuição para a decisão, o primeiro não destoa daqueles supra-analisados. Na realidade, ao afirmar que as regras são normas imediatamente descritivas e que os princípios são normas imediatamente finalísticas, Ávila vai ao encontro do critério do "tudo-ou-nada" de Dworkin, da colisão de princípios de Alexy, da ideia de Zagrebelsky - que afirma que os princípios não têm "suposto de fato" -, do dizer de Canaris sobre o modo de interação das normas e do critério de determinabilidade de Canotilho - segundo o qual as regras têm aplicação direta -, já que todos têm em comum a estrutura das regras, seja admitindo o elemento "suposto de fato", seja admitindo o elemento da "consequência jurídica", seja admitindo ambos. Nesse diapasão, ao dizer que os princípios são normas finalísticas, Ávila tacitamente aceita a ideia da "Lei de Colisão" de Alexy.

De igual forma, ao dizer que as regras, diferentemente dos princípios, na maioria das vezes dispensam uma justificação acentuada porque elas próprias contêm a justificação (no elemento "suposto de fato"), Ávila aceita seu caráter funcional e sua suscetibilidade de aplicação direta - ideias que correspondem, respectivamente, aos critérios da proximidade da ideia de direito e da determinabilidade na aplicação ao caso concreto, ambos expostos por Canotilho -, bem como acolhe as afirmações de Zagrebelsky acerca da sua aplicação mecânica e passiva e sobre a existência do suposto de fato.

No que diz respeito ao critério da medida de contribuição para a decisão, a afirmação de que os princípios não intentam gerar uma solução direta para o caso, mas buscam apenas contribuir para a decisão ao lado de outros elementos, mostra-se, senão, idêntica à afirmação de que os princípios são mandatos de otimização e, por isso, sua aplicação se daria ao máximo possível, sendo limitada pelas peculiaridades do caso concreto, sejam elas fáticas ou jurídicas, tal qual proclamou Alexy. Essa relação de identidade pode ser estabelecida, também, com os ensinamentos de Zagrebelsky, que afirma que os princípios são provocados a reagir diante do caso concreto, exatamente porque não possuem o elemento "suposto de fato".

No mesmo diapasão, o critério do grau de justificação de Ávila não se mostra inovador, pois a premissa de que os princípios sempre necessitam de justificação complexa decorre diretamente da sua qualidade de mandatos de otimização, que urge que sua aplicação se dê ao máximo possível, preceito lançado por Alexy.

Conclui-se, portanto, que os critérios clássicos apresentados para diferenciar princípios de regras, que se renovam com a inovação da ciência jurídica, não se 
mostram antagônicos entre si, mas harmoniosos, sendo todos aplicáveis, seja de maneira cumulativa, seja de maneira subsidiária, completando-se ou amparando-se uns aos outros, o que não pode ser rechaçado mesmo por aqueles que os reputam falhos.

About principles and rules: a critic about Humberto Ávila's theory of principles

Abstract: The neoconstitutionalism brought within it the pos-positivism, ideology that suggests a return to the jusnaturalism without appealing to metaphysical categories, proposing a moral reading of the law based on values. This way, the principles, whilom saw as mere informer policies without binding character, receive normative power, assuming a central role in the Constitutions. In this context, it is born the necessity of separate principles from rules. This essay is developed in the way to verify the doctrinaire thesis used to separate the normative species and develop a judicious analysis about them to verify their utility, and to present a critic to the Humberto Ávila's theory about principles and rules, pointing its fails and hits.

Keywords: Constitutional norms. Principles. Rules. Distinction. Neoconstitucionalism.

\section{Referências}

ALEXY, Robert. On the structure of legal principles. Ratio Juris, Oxford, v. 13, n. 3, p. 294-304, Sept. 2000.

ALEXY, Robert. Teoria de los derechos fundamentales. Madrid: Centro de Estúdios Constitucionales, 1993.

ALMEIDA FILHO, Agassiz de; CRUZ, Danielle da Rocha (Coords.). Estado de direito e direitos fundamentais: homenagem ao jurista Mário Moacyr Porto. 1. ed. Rio de Janeiro: Forense, 2005.

ÁVILA, Humberto. Teoria dos princípios: da definição à aplicação dos princípios jurídicos. 7. ed. São Paulo: Malheiros, 2007.

CANOTILHO, José Joaquim Gomes. Direito constitucional. 6. ed. Coimbra: Almedina, 1993.

CIANCIARDO, Juan. El ejercicio regular de los derechos: Análisis y crítica del conflictismo. 1. ed. Buenos Aires: Ad-Hoc, 2007.

CIANCIARDO, Juan. Principios y reglas: una aproximación desde los criterios distinción. Boletin Mexicano de Derecho Comparado, año XXXVI, n. 108, sept./dic. 2003. Nueva Serie.

DWORKIN, Ronald. Levando os direitos a sério. 3. ed. Tradução de Nelson Boeira. São Paulo: Martins Fontes, 2002.

MENDES, Gilmar Ferreira; COELHO, Inocêncio Mártires; BRANCO, Paulo Gustavo Gonet. Curso de direito constitucional. 2. ed. São Paulo: Saraiva, 2008.

NOVELINO, Marcelo. Direito constitucional. 2. ed. São Paulo: Método, 2008.

VIGO, Rodolfo Luis. Interpretação jurídica: do modelo juspositivista-legalista do século XIX às novas perspectivas. São Paulo: Revista dos Tribunais, 2005. 
Informação bibliográfica deste texto, conforme a NBR 6023:2002 da Associação Brasileira de Normas Técnicas (ABNT):

BERTUOL JUNIOR, Altecir. Sobre princípios e regras: uma crítica à teoria dos princípios de Humberto Ávila. A\&C - Revista de Direito Administrativo \& Constitucional, Belo Horizonte, ano 16, n. 63, p. 239-259, jan./mar. 2016.

Recebido em: 24.04.2015

Aprovado em: 12.07.2015 